\title{
Benefit, tolerance, and safety of hybrid argon plasma coagulation for treatment of Barrett's esophagus: US pilot study
}

\section{(ㄷ)(1) $(9$}

\author{
Authors \\ Chin, Zain Moosvi, Kenneth J. Chang \\ Institution \\ H. H. Chao Comprehensive Digestive Disease Center, \\ Division of Gastroenterology \& Hepatology, Department of \\ Medicine, University of California, Irvine, Orange, \\ California, United States
}

Toshitaka Shimizu, Jason B. Samarasena, Kyle J. Fortinsky, Rintaro Hashimoto, Nabil El Hage Chehade, Matthew A.

submitted 25.11.2019

accepted after revision 29.5.2020

\section{Bibliography}

Endosc Int Open 2021; 09: E1870-E1876

DOI 10.1055/a-1492-2450

ISSN 2364-3722

(C) 2021. The Author(s).

This is an open access article published by Thieme under the terms of the Creative Commons Attribution-NonDerivative-NonCommercial License, permitting copying and reproduction so long as the original work is given appropriate credit. Contents may not be used for commercial purposes, or adapted, remixed, transformed or built upon. (https://creativecommons.org/licenses/by-nc-nd/4.0/)

Georg Thieme Verlag KG, Rüdigerstraße 14,

70469 Stuttgart, Germany

\section{Corresponding author}

Kenneth J. Chang, MD, FASGE, FACG, Professor and Chief, Gastroenterology and Hepatology, University of California, Irvine, 333 City Blvd. West, Suite 400, Orange, CA 92868, USA Fax: +17144567753

kchang@uci.edu

\section{ABSTRACT}

Background and study aims A novel technique for Barrett's esophagus (BE) ablation, termed hybrid APC, has recently been developed. The aims of this US pilot study were to evaluate the efficacy, tolerance and safety of hybrid APC for the treatment of BE.

Patients and methods Patients with biopsy-proven BE referred to our tertiary care center over a 12-month period for mucosal ablation were eligible for this study. Efficacy of ablation was measured on follow-up endoscopy by demonstrating either a reduction of visible BE or biopsies proving complete resolution of intestinal metaplasia (CRIM). To evaluate tolerance and safety, patients were called on post-procedure days 1 and 7 .

Results Twenty-two patients with BE (4.5\% intramucosal carcinoma, $31.8 \%$ high-grade dysplasia, $18.1 \%$ low-grade dysplasia, $36.3 \%$ non-dysplastic, $9.1 \%$ indefinite for dysplasia) underwent 40 treatments with hybrid APC. All patients had endoscopic improvement of BE disease and 19 of 22 patients $(86.4 \%)$ achieved CRIM. With regard to tolerance, average pain scores ( 0 to 10 scale) on follow-up were 2.65 and 0.62 on days 1 and 7 , respectively. With regards to safety, there were two treatment-related strictures (9.1\%) that required a single balloon dilation.

Conclusions Hybrid APC appears to be promising in the treatment of BE. The ablation protocol used in this study demonstrated efficacy, tolerability, and a safety profile similar to radiofrequency ablation. Given the significant price difference between hybrid APC and other modalities for Barrett's ablation, this modality may be more cost-effective. These results warrant further study in a large prospective multicenter trial.

\section{Introduction}

The incidence of esophageal adenocarcinoma has increased in the United States over the past decade [1]. Once diagnosed, esophageal adenocarcinoma has a poor prognosis with a less than a $25 \% 5$-year survival after a diagnosis of locally advanced disease. There remains a greater need to identify and screen for Barrett's esophagus (BE) in order to treat this precursor, and prevent its progression to adenocarcinoma. Endoscopic therapy for BE has been shown to be safe and effective. Currently, treatment mainly relies on a two-step approach that consists of endoscopically resecting any nodular lesions or visible flat neoplasia then thermally ablating non-neoplastic BE segments. The latter phase of treatment aims at reducing the rates of recurrent neoplastic BE and achieving complete remission of 
intestinal metaplasia (CRIM). The most widely used tool for BE ablation is radiofrequency ablation (RFA) [2].

RFA uses a balloon-based or focal device that uses energy to ablate tissue to a consistent depth so as to minimize submucosal injury and the risk of stricture formation or bleeding. A multicenter, sham-controlled trial demonstrated that RFA contributes to the eradication of BE in $77.4 \%$ of patients [1]. Despite this, the rate of stricture formation post-RFA remains in the $5 \%$ to $10 \%$ range and the recurrence rate reached $29.1 \%$ in a nationwide US study [1, 3-6].

Argon plasma coagulation (APC) is an alternative procedure that has been used for the treatment of BE. This modality is a contact-free, operator-dependent endoscopic ablation technique that utilizes a jet of ionized Argon gas to generate thermal energy for the ablation of metaplastic tissue. APC has been commonly used to treat small segments and islands of $B E$ [7]. Given the variable depth of injury associated with APC application and the increased risk of strictures or perforation, it has not been used as a mainstream technique for the treatment of large segments of BE. A novel hybrid ablation method based on the combination of APC and submucosal saline injection (hybrid APC) has been recently developed to overcome some of the disadvantages of standard APC ablation [8]. Prior to ablation, the mucosa is raised with the aid of a needle-less highpressure water jet. In theory, the submucosal cushion enables Barrett's mucosa to be ablated to a sufficient depth with high energy input without causing damage to the deep submucosa and muscularis layer. A study conducted by Norton and colleagues showed that hybrid APC leads to a lower depth of tissue damage, which potentially could lead to lower rates of strictures compared to standard APC procedures [9]. However, the current literature on this technique is limited and furthermore, there currently is not a standardized protocol for hybrid APC of $B E[10]$. The aim of the present study was to evaluate the efficacy and safety of hybrid APC for BE ablation.

\section{Patients and methods}

\section{Patients}

Patients aged 18 to 80 years with biopsy-proven BE were included in this study. Both treatment-naïve patient as well as patients who had received other types of treatment of $B E$, such as endoscopic resection, RFA, and cryotherapy, were included. Exclusion criteria included patients with coagulation disturbances, active nodular lesions, esophageal cancer history, strictures, poor healing after previous endoscopic treatment, as well as patients who had undergone esophageal surgery or endoscopic plication or suturing procedures ( Table 1). All the procedures were performed at the Comprehensive Digestive Disease Center, University of California, Irvine by two interventional endoscopists, K.C. and J.S. The study was approved by the institutional review board (IRB) at the University of California, Irvine.
- Table 1 Inclusion and exclusion criteria for the present study.

\begin{tabular}{|c|c|}
\hline Inclusion criteria & Exclusion criteria \\
\hline $\begin{array}{l}\text { Written informed consent to be } \\
\text { part of the study and undergo } \\
\text { repeated diagnostic and thera- } \\
\text { peutic upper gastrointestinal } \\
\text { endoscopy for Barrett's esoph- } \\
\text { agus }\end{array}$ & Age $<18$ \\
\hline \multirow{7}{*}{$\begin{array}{l}\text { Naïve or previously treated resi- } \\
\text { dual non-neoplastic Barrett's } \\
\text { esophagus of at least } 1 \mathrm{~cm} \text { ex- } \\
\text { tent }\end{array}$} & Pregnancy \\
\hline & Coagulation disturbances \\
\hline & Esophageal cancer history \\
\hline & $\begin{array}{l}\text { Active nodular or neoplastic } \\
\text { lesion }\end{array}$ \\
\hline & History of strictures \\
\hline & $\begin{array}{l}\text { Poor healing after prior endo- } \\
\text { scopic treatment }\end{array}$ \\
\hline & $\begin{array}{l}\text { Prior transoral incisionless fun- } \\
\text { doplication (TIF) or antireflux } \\
\text { procedure using endoscopic su- } \\
\text { turing }\end{array}$ \\
\hline
\end{tabular}

\section{Technique}

\section{Endoscopic evaluation}

A diagnostic gastroscope (GIF-HQ190; Olympus) was used for all procedures. An electrosurgical unit with an APC2-unit (VIO 300 D) with ERBEJET2 system (Erbe Elektromedizin, Tuebingen, Germany) were used for hybrid APC procedures. A baseline endoscopy was first performed to identify areas of residual BE. The length of each BE segment was then measured, and BE segments were classified using the Prague C\&M criteria [11]. Targeted biopsies were carried out for any lesion that was suspicious for high grade dysplasia or cancer based on virtual chromoendoscopy or confocal laser endomicroscopy.

\section{Hybrid APC ablation}

The hybrid APC procedure was performed as follows: Thermal marking of the outer limits of the target area was performed using low-wattage APC (Soft Coagulation $30 \mathrm{~W}$ at a flow rate of 0.8 to $1.0 \mathrm{~L} / \mathrm{min}$ ). Next, injection of $0.9 \%$ methylene blue tinted saline solution was performed using the needleless highpressure water jet system (ERBEJET 2, Effect 40-50, Erbe Elektromedizin, Tuebingen, Germany) ( $\triangleright$ Fig.1). The amount of fluid used varied so as to create a visible cushion underneath the mucosa.

The mucosa was ablated using contact free thermal argonbased thermal energy with the hybrid APC probe (Pulsed APC, Effect 2, 60 Watt). The treatment was carried out in either longitudinal strips or circumferentially until a visible coagulation effect was seen ( $\mathbf{F i g . 2}$ ). The ablation zone coagulum was mechanically scraped off with a transparent cap on the tip of the endoscope ( $>$ Fig.3). A second pass of ablation was applied over the Barrett's mucosa but at a lower power than that used during the first pass (pulsed APC, effect 2, $40 \mathrm{~W}$ ). 


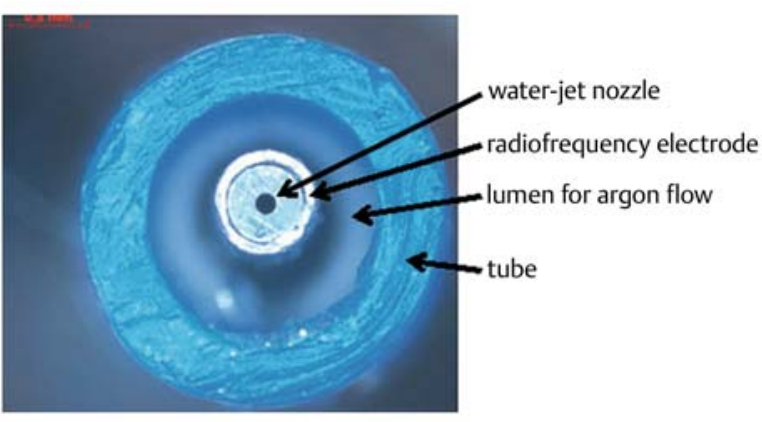

- Fig. 1 Cross-section of the needleless water-jet flexible probe used for submucosal injection prior to APC.

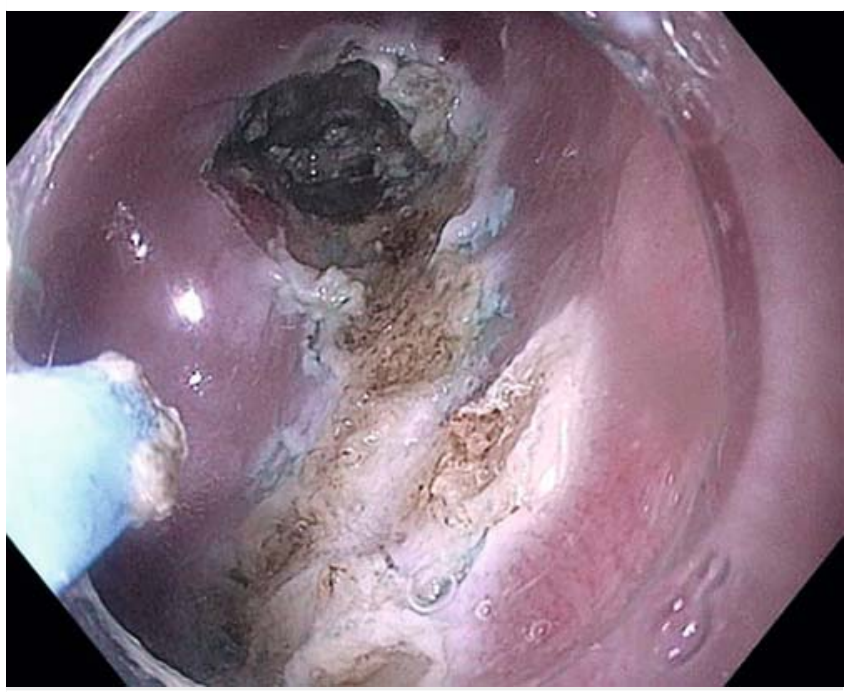

- Fig. 2 Endoscopic view of Barrett's esophagus after application of hybrid APC.

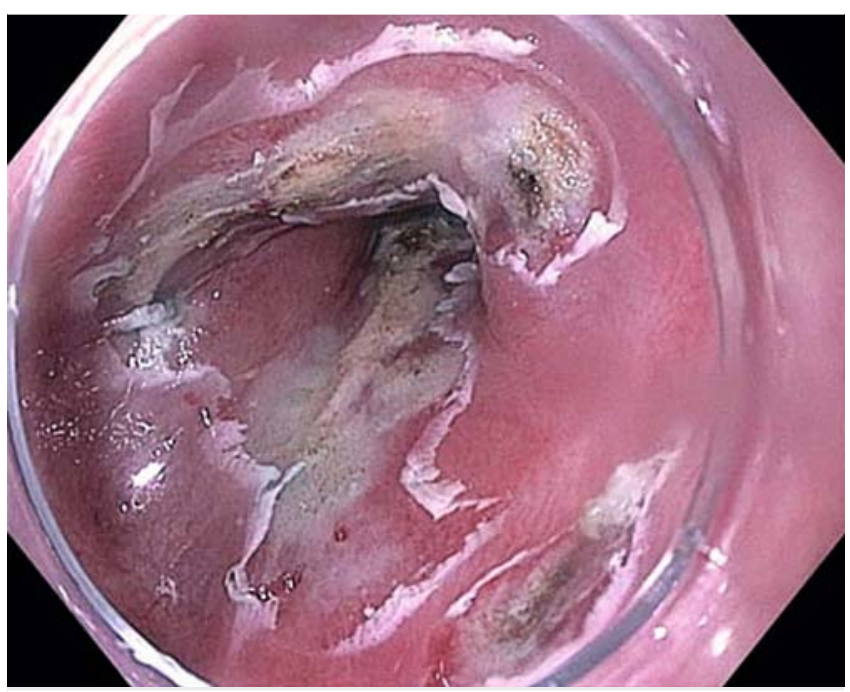

- Fig. 3 Endoscopic view of Barrett's esophagus after scraping mucosal layer.
The procedure was performed under general anesthesia. Patients were discharged on the same day of the procedure. A high-dose proton pump inhibitor, $40 \mathrm{mg}$ BID, and sucralfate $1 \mathrm{~g}$ QID were prescribed after the procedures to all patients.

\section{Follow-up}

During the first week post-procedure, patients were followed up on days 1 and 7 to check for any reported adverse events (AEs) such as bleeding, pain, odynophagia, fever, or dysphagia. Patients were also asked to score their pain on a scale of 1 to 10. They were also asked about taking opiate analgesics for pain control if needed. At least 3 months after completion of Barrett's ablation, endoscopy was carried out for evaluation. During the follow-up procedure, the esophagus was examined for any visible residual $\mathrm{BE}$ or any treatment-related changes. If residual BE was observed during this examination, additional hybrid APC was performed. If no visible BE was noted, biopsies at the $\mathrm{z}$ line and biopsies in at least one level in the area of the former BE were then taken for histopathologic assessment. Histological processing was carried out by pathologists highly experienced in the diagnosis of Barrett's neoplasia.

\section{Statistical analysis}

The main endpoints of this pilot study were evaluation of the safety and efficacy of hybrid APC in ablating BE. Efficacy was defined as the proportion of patients achieving CRIM after hybrid APC. Evidence for CRIM was determined based on histologic evaluation. The efficacy of hybrid APC was also evaluated in terms of the average number of sessions needed to achieve CRIM. Safety was evaluated by determining the proportion of patients who developed complications observed during the treatment or on follow up evaluation such as stricture, perforation, and bleeding.

A complete descriptive analysis of the data was performed. The results are reported in relative frequencies. Various means, ranges, as well as standard deviations were measured and reported. The change in the values of $C$ and $M$ of the Prague classification pre- and post- procedure were evaluated on the basis of a two-sided test with a significance level of 0.05 .

\section{Results}

A total of 22 patients with biopsy-proven BE underwent a total of 40 treatment sessions with hybrid APC. The average age was 67.8 years and $81.8 \%$ of the patients were male. The pretreatment values of $C$ and $M$ of the Prague classification ranged from C0M1 to C6M8. The subjects were classified according to their baseline histopathologic biopsy results: $4.5 \%$ intramucosal carcinoma, $31.8 \%$ high-grade dysplasia, $18.1 \%$ low-grade dysplasia, $9.1 \%$ indefinite for dysplasia, and $36.4 \%$ non-dysplastic. The patients were further classified according to whether they had undergone any prior treatment for BE. Half of the patients had undergone prior RFA, 22.7\% prior EMR, 9.1\% prior ESD, $13.6 \%$ prior cryotherapy, and $36.4 \%$ were treatment naïve ( Table 2).

The average procedure treatment times were 23.9 and 14.83 minutes at the index and first follow-up procedures, 
- Table 2 Overview of study patients and baseline characteristics prior to first hybrid APC session.

\begin{tabular}{|c|c|}
\hline \multicolumn{2}{|l|}{ Characteristics } \\
\hline \multirow[t]{2}{*}{ Gender distribution } & Female $=18.1 \%(4 / 22)$ \\
\hline & Male $=81.8 \%(18 / 22)$ \\
\hline Age & Mean $=67.8$ years old \\
\hline $\begin{array}{l}\text { Extent of BE prior to hybrid } \\
\text { APC (Prague classification) }\end{array}$ & C0.73 M1.99 \\
\hline \multirow{5}{*}{$\begin{array}{l}\text { Type of treatment prior to } \\
\text { hybrid APC }\end{array}$} & Prior RFA = $50 \%(11 / 22)$ \\
\hline & Prior EMR = $22.7 \%$ (5/22) \\
\hline & Prior ESD = $9 \%(2 / 22)$ \\
\hline & Prior cryotherapy $=13.6 \%(3 / 22)$ \\
\hline & No prior treatment $=36 \%(8 / 22)$ \\
\hline \multirow[t]{5}{*}{ Baseline BE pathology } & Non-dysplastic = $36.3 \%(8 / 22)$ \\
\hline & Indeterminate = $9.1 \%(2 / 22)$ \\
\hline & Low-grade dysplasia $=36.3 \%(8 / 22)$ \\
\hline & High-grade dysplasia $=18.1 \%(4 / 22)$ \\
\hline & Intramucosal cancer $=4.5 \%(1 / 22)$ \\
\hline
\end{tabular}

APC, argon plasma coagulation; BE, Barrett's esophagus; RFA, radiofrequency ablation; EMR, endoscopic mucosal resection; ESD, endoscopic submucosal dissection.

respectively. With regard to efficacy, 19 of 22 patients (86.4\%) achieved CRIM according to histopathology. Twelve patients achieved histopathologic CRIM after one hybrid APC procedure, two patients after two procedures, one patient after three procedures, and four patients after four treatment procedures ( $\triangleright$ Table 3 ). In the group that achieved CRIM, an average of 1.2 treatment sessions was needed. The average follow-up time for all subjects was 134.7 days. At the first follow-up endoscopy, all patients had endoscopically evident improvement of $\mathrm{BE}$ disease with regard to the average length of $\mathrm{BE}$ pre- and post-procedure. The respective $C$ and $M$ values of the Prague criteria endoscopy were C0.95 and M2.84 at index endoscopy and $\mathrm{C} 0.23$ and M0.66 during the first follow-up. There was a $77.9 \%$ reduction in circumference $(C)$ of $B E(P=$ $0.001)$ and an $80.2 \%$ reduction in maximal extent $(M)$ of $B E(P$ $=0.0003$ ). Three patients did not achieve CRIM ( $>$ Table 4).

With regard to safety, there were two treatment-related strictures that required a single session of balloon dilation; thus, the stricture rate associated with hybrid APC in this study was $9.1 \%(2 / 22)$ ( $>$ Table 3 ). There were no reported bleeding or perforation events. With regard to tolerance, the average pain scores on days 1 and 7 post-procedure were 2.65 and 0.62 , respectively, in 10 . Five of 22 patients $(22.7 \%$ ) reported taking analgesics for pain control.

\section{Discussion}

The ideal tool for BE eradication still remains to be established. Thermal ablation of BE with RFA after endoscopic resection of visible nodular neoplasia has been the mainstay of contemporary BE therapy. In patients with dysplastic BE, RFA is associated with a moderate to high rate of complete eradication of both dysplasia and intestinal metaplasia and a reduced risk of disease progression [1]. Although this procedure is safe, the incidence of the stricture formation post-RFA has been reported as up to $5 \%$ to $10 \%$ [2]. Furthermore, the recurrence rate of $\mathrm{BE}$ in patients treated with RFA has been reported to be $10.8 \%$ per year after achieving CRIM [6]. Although RFA has revolutionized the management of $B E$ in the past decade, it still may not be the ideal tool for this disease in the future.

In this US pilot study, hybrid APC was able to achieve CRIM in $81.8 \%$ of patients and this rate is comparable to other modalities currently available for BE eradication. Standard APC without prior submucosal injection has been reported to achieve a complete BE ablation rate of $77 \%$ in a single multicenter German study [12]. The major complication rate is this study, however, was $9.8 \%$ including bleeding, stricture and a perforation. In a single center German study by Manner et al. evaluating hybrid APC for BE, the rate of CRIM was found to be $78 \%$. In a meta-analysis that reported the efficacy of RFA in a total of 18 studies and 3802 patients, complete eradication of intestinal metaplasia was observed in $78 \%$ of patients [4]. According to a UK Registry on RFA, the rate was lower with a rate of $62 \%$ at 12 month follow-up [4]. Therefore, hybrid APC may lead to at least similar efficacy results to those achieved using RFA.

In this study, hybrid APC had a favorable safety profile. Stricture formation was observed in two patients with a rate of $9.1 \%$ and no other significant complications were noted. One of the patients with stricture had previously undergone a cryotherapy procedure and the lumen was notably narrowed at the time of initial hybrid APC. In each of the patients, the strictures were managed effectively with a single balloon dilation session. This stricture rate is similar to previous APC-only studies with reported stricture rates of $4 \%$ to $9 \%[13,14]$. This rate also compares well with the rate of stricture formation post-RFA, which has been consistently reported in the $5 \%$ to $10 \%$ range [2].

The study by Manner et al. demonstrated a stricture rate of only $2 \%$ post-hybrid APC treatment [9]. The authors reported that in their protocol the scraping of coagulum remnants after first ablation was not carried out for the first patients enrolled and this could account for their decreased rate of stricture formation. Also, of note with this study was the exclusion of 10 patients that had enrolled for a number of different reasons including poor mucosal healing after hybrid APC treatment. As a result, the stricture rate in their study may be lower than expected.

There were no major AEs in our study, aside from the two patients with strictures. No perforations or significant bleeding occurred during or after the procedures. This is in contrast to a multicenter trial on APC for non-dysplastic BE in which major complications were observed in $10 \%$ of patients; two bleeding complications, two esophageal strictures, and one perforation. 
Table 3 Results in all patients.

\begin{tabular}{|c|c|c|c|c|c|c|c|c|}
\hline Initials & Age & Sex & $\begin{array}{l}\text { Initial } \\
\text { Dx }\end{array}$ & $\begin{array}{l}\text { Prague } C \\
\text { before Tx }\end{array}$ & $\begin{array}{l}\text { Prague } M \\
\text { before } T x\end{array}$ & $\begin{array}{l}\text { Prior proce- } \\
\text { dures }\end{array}$ & $\begin{array}{l}\text { \# of sessions to } \\
\text { achieve CRIM }\end{array}$ & $\begin{array}{l}\text { Complica- } \\
\text { tions }\end{array}$ \\
\hline \multicolumn{9}{|c|}{ Treatment naive } \\
\hline - WB & 66 & M & LGD & 0.5 & 4.5 & Naïve & 1 & Stricture \\
\hline - FD & 74 & M & ND & 1 & 3 & Naïve & 2 & None \\
\hline - DT & 67 & $\mathrm{~F}$ & ND & 6 & 8 & Naïve & 4 & None \\
\hline - $\mathrm{NH}$ & 68 & $\mathrm{~F}$ & LGD & 0 & 1 & Naïve & 4 & None \\
\hline - NC & 65 & M & ND & 0 & 1 & Naïve & 1 & None \\
\hline - $\mathrm{RC}$ & 69 & M & ND & 0 & 1 & Naïve & 1 & None \\
\hline . VH & 65 & $\mathrm{~F}$ & ND & 4 & 6 & Naïve & 2 & None \\
\hline - $\mathrm{SH}$ & 60 & M & ND & 1 & 2 & Naïve & 1 & None \\
\hline \multicolumn{9}{|c|}{ Previously treated } \\
\hline - ES & 68 & M & IND & 1 & 1 & RFAx 1 & 3 & None \\
\hline . DN & 82 & M & ND & 1 & 1 & $\begin{array}{l}\text { RFAx4 } \\
\text { Cryotherapy x } 1\end{array}$ & $\mathrm{~N} / \mathrm{A}$ & None \\
\hline . NT & 80 & $M$ & LGD & 1 & 2 & RFAx 1 & $\mathrm{~N} / \mathrm{A}$ & None \\
\hline - DF & 69 & $M$ & IND & 1 & 2 & RFAx3 & 1 & None \\
\hline - MS & 69 & $M$ & ND & 0 & 1 & RFAx2 & 1 & None \\
\hline - DK & 49 & $M$ & HGD & 0 & 3 & RFAx 1 & 1 & None \\
\hline - $A E$ & 77 & $M$ & HGD & 4 & 4 & $\begin{array}{l}\text { RFAx3 } \\
\text { EMR } 3\end{array}$ & $\mathrm{~N} / \mathrm{A}$ & None \\
\hline - SJ & 68 & M & HGD & 0 & 1 & $\begin{array}{l}\text { RFAx2 } \\
\text { Cryotherapy x } 1\end{array}$ & 1 & None \\
\hline . $L R$ & 60 & $M$ & HGD & 0 & 1 & $\begin{array}{l}\text { RFAx3 } \\
\text { EMRx1 }\end{array}$ & 1 & None \\
\hline - VM & 64 & M & HGD & 0 & 1 & EMRx1 & 1 & None \\
\hline - BN & 57 & M & Adeno & 0.5 & 7 & $\begin{array}{l}\text { ESD } 1 \\
\text { Cryotherapy } x 1\end{array}$ & 1 & Stricture ${ }^{1}$ \\
\hline - LM & 73 & $\mathrm{~F}$ & LGD & 0 & 7 & $\begin{array}{l}\text { RFAx3 } \\
\text { EMR } 1\end{array}$ & 4 & None \\
\hline - $M L$ & 71 & $M$ & HGD & 0 & 4 & RFAx1 & 4 & None \\
\hline - $\mathrm{KR}$ & 72 & $M$ & HGD & 0 & 1 & $\begin{array}{l}\text { EMRx1 } \\
\text { ESDx1 }\end{array}$ & 1 & None \\
\hline Mean & 67.8 & F: $18.18 \%$ & - & 0.95 & 2.93 & & & \\
\hline
\end{tabular}

One possible explanation for this improved safety profile may have been the submucosal injection prior to ablation. With hybrid APC technique, the mucosa is raised with the aid of a needle-less high-pressure water jet. In theory, the submucosal cushion enables Barrett's mucosa to be ablated with high energy without causing damage to the larger deep submucosal arteries and muscularis layer.

In regard to patient tolerability, the hybrid APC procedures were tolerated well. The average chest pain scores reported on days 1 and 7 after the first session were 2.65 and 0.62 of 10 , respectively. These values appear to be similar to pain scores with RFA. In a multicenter study conducted on dysplastic patients undergoing RFA, pain scores often were 2.3 and 0 on days 1 and 8 post-procedure, respectively [1]. As expected, in our study, the chest pain scores appeared to correlate with the amount of ablation performed during the session.

Hybrid APC is potentially more cost-effective than RFA. The results of our study and the hybrid APC study by Manner and 
Table4 Results in patients without CRIM.

\begin{tabular}{|c|c|c|c|c|c|c|c|c|}
\hline $\begin{array}{l}\text { Patient } \\
\#\end{array}$ & Age & Sex & $\begin{array}{l}\text { Initial } \\
\text { Dx }\end{array}$ & $\begin{array}{l}\text { Prague C } \\
\text { before Tx }\end{array}$ & $\begin{array}{l}\text { Prague } M \\
\text { before Tx }\end{array}$ & $\begin{array}{l}\text { Prior } \\
\text { procedures }\end{array}$ & $\begin{array}{l}\text { \# of sessions to } \\
\text { achieve CRIM }\end{array}$ & Complications \\
\hline 1 & 82 & M & ND & 1 & 1 & $\begin{array}{l}\text { RFAx4 } \\
\text { Cryotherapy } x 1\end{array}$ & None & $\begin{array}{l}\text { Decided to not pursue } \\
\text { further treatment }\end{array}$ \\
\hline 2 & 80 & M & LGD & 1 & 2 & RFAx1 & None & $\begin{array}{l}\text { Decided to not pursue } \\
\text { further treatment }\end{array}$ \\
\hline 3 & 77 & M & HGD & 4 & 4 & $\begin{array}{l}\text { RFAx3 } \\
\text { EMRx3 }\end{array}$ & None & $\begin{array}{l}\text { Decided to not pursue } \\
\text { further treatment }\end{array}$ \\
\hline Mean & 79.7 & M: $100 \%$ & - & 2.0 & 2.3 & & & \\
\hline
\end{tabular}

collegues demonstrate comparable efficacy and safety of hybrid APC to RFA, while the cost per case to perform hybrid APC is less than the cost of RFA [9]. The device cost for one ERBE hybrid APC probe (Part \#20150-215) is $\$ 489.00$ and the cost for the Erbejet pump cartridge (Part \#20150-300) required for use is $\$ 110.70$, which leads to a sum of $\$ 599.70$ for disposable equipment. In comparison, RFA catheters range from $\$ 1,000$ to $\$ 2,100$ for the disposable equipment needed per case. The capital cost for the BARRX generator is $\$ 130,000$. The capital cost for the ERBE VIO electrosurgical unit with the APC2 and ERBE JET component (needed for hybrid APC) is $\$ 83,000$ If an institution already has the ERBE VIO with APC, the additional cost for the ERBE JET is $\$ 46,000$. As a result, hybrid APC may be a more cost effective over the current standard RFA.

The present study has several limitations. This was a singlecenter study of a small group of patients with procedures performed by expert interventional endoscopists. Results therefore may not be generalizable to community physicians with less training. Another limitation was that patients did not have long-term follow-up so we were unable to determine recurrence rates for BE with hybrid APC. A further limitation was that only $36 \%$ of patients in our sample were treatment naïve. The fact that patients had been treated before with prior modalities may lead to an advantage with reaching CRIM. However, of note, five patients enrolled in this study were actually patients that had not responded well to other modalities; therefore, this subset may have actually been a more difficult subset to treat.

There were eight patients with non-dysplastic BE in our study. Three of the patients had long-segment disease and the long-term risk of disease progression was felt to be higher than the risk of treatment. The authors acknowledge that the treatment of non-dysplastic Barrett's is controversial, and guidelines suggest case-by-case assessment is warranted. In most cases, patients were very concerned about their risk of disease progression and wanted to move forward with Barrett's eradication. They were given the options of surveillance or treatment with hybrid APC as part of an experimental protocol, under- standing that insurance would not approve RFA in many of these cases.

\section{Conclusions}

In conclusion, hybrid APC appears to be promising for treatment of BE. The ablation protocol used in this study demonstrated efficacy, tolerability, and a safety profile similar to RFA. Given the significant price difference between hybrid APC and other modalities for BE ablation, this modality may be more cost effective. These results warrant further study in a large prospective multicenter trial.

\section{Competing interests}

Dr. Chang is a consultant for ERBE.

\section{References}

[1] Shaheen NJ, Sharma P, Overholt BF et al. Radiofrequency ablation in Barrett's esophagus with dysplasia. N Engl J Med 2009; 360: 22772288

[2] Singh T, Sanaka MR, Thota PN. Endoscopic therapy for Barrett's esophagus and early esophageal cancer: Where do we go from here? World J Gastrointest Endosc 2018; 10: 165-174

[3] Shaheen NJ, Overholt BF, Sampliner RE et al. Durability of radiofrequency ablation in Barrett's esophagus with dysplasia. Gastroenterology 2011; 141: 460-468

[4] Haidry RJ, Dunn JM, Butt MA et al. Radiofrequency ablation and endoscopic mucosal resection for dysplastic barrett's esophagus and early esophageal adenocarcinoma: outcomes of the UK National Halo RFA Registry. Gastroenterology 2013; 145: 87-95

[5] Strauss AC, Agoston AT, Dulai PS et al. Radiofrequency ablation for Barrett's-associated intramucosal carcinoma: a multi-center followup study. Surg Endosc 2014; 28: 3366-3372

[6] Tan MC, Kanthasamy KA, Yeh AG et al. Factors associated with recurrence of Barrett's esophagus after radiofrequency ablation. Clin Gastroenterol Hepatol 2019; 17: 65-72 
[7] Manner H, May A, Miehlke S et al. Ablation of nonneoplastic Barrett's mucosa using argon plasma coagulation with concomitant esomeprazole therapy (APBANEX): a prospective multicenter evaluation. Am J Gastroenterol 2006; 101: 1762-1769

[8] Manner H, Neugebauer A, Scharpf M et al. The tissue effect of argonplasma coagulation with prior submucosal injection (Hybrid APC) versus standard APC: A randomized ex-vivo study. United European Gastroenterol J 2014; 2: 383-390

[9] Norton ID, Wang L, Levine SA et al. Efficacy of colonic submucosal saline solution injection for the reduction of iatrogenic thermal injury. Gastrointest Endosc 2002; 56: 95-99

[10] Manner H, May A, Kouti IC et al. Efficacy and safety of hybrid APC for the ablation of Barrett's esophagus. Surg Endosc 2016; 30: 13641370
[11] Sharma P, Dent ], Armstrong D et al. The development and validation of an endoscopic grading system for Barrett's esophagus: the Prague C \& M criteria. Gastroenterology 2006; 131: 1392-1399

[12] Manner H, May A, Miehlke S et al. Ablation of nonneoplastic Barrett's mucosa using argon plasma coagulation with concomitant esomeprazole therapy (APBANEX): a prospective multicenter evaluation. Am J Gastroenterol 2006; 101: 1762-1769

[13] Pereira-Lima JC, Busnello JV, Saul C et al. High power setting argon plasma coagulation for the eradication of Barrett's esophagus. Am J Gastroenterol 2000; 95: 1661-1668

[14] Schulz H, Miehlke S, Antos D et al. Ablation of Barrett's epithelium by endoscopic argon plasma coagulation in combination with high-dose omeprazole. Gastrointest Endosc 2000; 51: 659-663 